\title{
COBERTURA VEGETAL E QUALIDADE DE VIDA: CIDADE DE GUANAMBI, SEMIÁRIDO BAIANO
}

\author{
Carlos Magno Santos Clemente \\ Centro Universitário UniFG, Observatório UniFG do Semiárido Nordestino, Guanambi, BA, Brasil \\ carlosmagno.clemente@gmail.com \\ Deborah Marques Pereira \\ Centro Universitário UniFG, Observatório UniFG do Semiárido Nordestino, Guanambi, BA, Brasil \\ deborah.mp.fg@gmail.com
}

Centro Universitário UniFG, Programa de Pós-Graduação Strictu Sensu em Direito da UniFG, Guanambi, BA, Brasil
hellen.magalhaes01@gmail.com

\section{RESUMO}

A presença da cobertura vegetal em áreas urbanas é um indicador relevante para caracterizar a qualidade de vida da população residente nas cidades. Porém, no Brasil as políticas públicas relativas à cobertura vegetal urbana apresentam-se de forma deficitária e pouco expressiva. Desse modo, a pesquisa teve como objetivo quantificar e analisar a cobertura vegetal na cidade de Guanambi (BA). Como instrumentos de análises foram utilizados os softwares ENVI 5.5 e ArcGIS 10.2.2. Para tanto, foram realizados cálculos de Índice de Cobertura Vegetal (ICV) e Índice de Cobertura Vegetal por Habitante (ICVH) para quantificar a vegetação. Observou-se que os valores encontrados para ICVH foram abaixo dos padrões recomendados pela Sociedade Brasileira de Arborização Urbana (12,63 $\mathrm{m}^{2} / \mathrm{hab}$.). Além disso, foram constatados valores baixos de ICV em loteamentos recentes e nas regiões periféricas. Por outro lado, há áreas com expressiva concentração espacial de cobertura vegetal na cidade. Desse modo, o estudo reforça a necessidade de políticas públicas efetivas para garantir a conservação e o aumento da cobertura vegetal na cidade de Guanambi, principalmente nas áreas periféricas e nos loteamentos recentes.

Palavras-chave: Sistema de Informação Geográfica. Índice de Vegetação. Meio ambiente urbano. Políticas públicas.

\section{VEGETABLE COVERAGE AND QUALITY OF LIFE: CITY OF GUANAMBI, BAHIA SEMIARID}

\begin{abstract}
The presence of vegetation cover in urban areas is a relevant indicator to portray the quality of life related to the population living in cities. However, in Brazil, public policies related to urban vegetation cover are deficient and little expressive. Thus, the research aimed to quantify and analyze the vegetation cover in the city of Guanambi (BA). Were used as instruments of analysis, ENVI 5.5 and ArGIS 10.2.2 softwares. Therefore, calculations of Vegetation Coverage Index - VCl and Vegetation Coverage Index per Inhabitant - VCII were performed to quantify Guanambi the vegetation. Observed that the values found for VCIl were below the recommended standards by the Brazilian Society of Urban Forestry $\left(12,63 \mathrm{~m}^{2} / \mathrm{hab}\right.$.). Beyond that, low $\mathrm{VCl}$ values were detected in recent allotments and in the peripheral regions. On the other side, there are areas in the city with significant spatial concentration of vegetation cover presented in a spread-out way. This way, the study reinforces the need for attention and
\end{abstract}


effective public policies to ensure the conservation and increase of vegetation cover in the city of Guanambi, especially in the peripheral areas and recent lots.

Keywords: Geographic Information System. Vegetation Index. Urban environment. Public policies.

\section{INTRODUÇÃO}

As cidades brasileiras vivenciaram, a partir da década de 1950, o fenômeno da urbanização, caracterizado pela rápida concentração de pessoas nos espaços urbanos em detrimento da evacuação das zonas rurais (MARICATO, 2003). Este fenômeno foi acompanhado por um planejamento deficitário que evidenciou várias problemáticas urbanas, passando a interferir na qualidade de vida nas cidades, entre estes os que integram as dinâmicas ambientais (PIVETA e SILVA FILHO, 2002). Entre os agravantes, a ascensão das atividades imobiliárias desordenadas acarreta a diminuição significativa dos espaços verdes das áreas urbanas, restringindo à cobertura vegetal pública de praças, sistemas viários e reservas florestais urbanas (MILANO e DALCIN, 2000).

Conforme Moura e Nucci (2005), muitas discussões acerca da delimitação conceitual sobre a vegetação urbana são apresentadas de forma divergente, pois termos como "espaços verdes"; "espaços livres"; "cobertura vegetal"; e "arborização" são empregados de maneira aleatória, o que torna dificultosa a estruturação de termos adequados e precisos nas políticas públicas ambientais nas cidades (CAVALHEIRO e DEL PICCHIA, 1992).

Desse modo, as "áreas verdes" têm como características a predominância de árvores com fins estéticos, ecológicos e de lazer. Para tanto, a vegetação e o solo não edificado e permeável devem ocupar no mínimo $70 \%$ do total da área, além de ser de uso comum por toda a população (MOURA e NUCCI, 2005). Neste sentido, as áreas verdes são consideradas como espaços públicos ou privados capazes de propiciar bem-estar para a população citadina, influenciando o microclima e a luminosidade do espaço urbano (OLIVEIRA, 1996).

Em relação às "áreas livres" Cavalheiro e Del Picchia (1992) definem que se trata de uma expressão ampla, apta a englobar desde as áreas verdes até as águas superficiais. Para Richter (1981) afirma que os espaços livres são caracterizados pela composição de uma diversidade de elementos verdes e por diferentes espaços livres isolados em assentamentos urbano-industriais, podendo comportar toda a área livre não edificada (COSTA e FERREIRA, 2007).

Neste sentido, o conceito de "arborização" apresenta um caráter mais restrito, pois a arborização é caracterizada pela composição de vegetação arbóreo-arbustiva que acompanha as vias públicas da cidade, seguidos por parâmetros e normas urbanísticas, tais como a distância entre as copas das árvores e redes de alta e baixa tensão, escolha de espécies que não sejam frutíferas, e ainda, sendo preferíveis as espécies da flora nativa, dentre outras (COSTA e FERREIRA, 2007).

Em uma abordagem conceitual cartográfica, considera-se como cobertura vegetal a projeção do verde em cartas planimétricas que podem ser facilmente identificadas por meio de fotografias aéreas ou produtos orbitais (NUCCl e CAVALHEIRO, 1999). Para tanto, considera-se elementos como a escala, índices de cobertura vegetal, localização e o desenho dos fragmentos de vegetação ( $\mathrm{NUCCl}$ e CAVALHEIRO, 1999). Vale ressaltar que a expressão "cobertura vegetal" se torna um conceito amplo nos estudos ambientais, já que compreende toda a cobertura existente em Unidades de Conservação -UC's, urbanas e rurais (NUCCI e CAVALHEIRO, 1999). Assim, os benefícios da presença da cobertura vegetal 
em um tecido são capazes de (re)estabelecer relações entre o homem-meio, melhorando o bem-estar (COSTA e FERREIRA, 2009).

Nesse contexto, o presente estudo teve como objetivo quantificar e analisar a cobertura vegetal e a arborização na cidade de Guanambi, localizada no semiárido baiano. Salienta-se que para as análises foram utilizadas as definições de cobertura vegetal e arborização supramencionadas, pois são conceitos capazes de abranger os anseios metodológicos do presente artigo.

Assim, a pesquisa em comento se justifica pela necessidade técnica e científica de conhecer, difundir e fomentar novos estudos sobre cobertura vegetal e a arborização na cidade de Guanambi, instigando políticas públicas que busquem a melhoria da qualidade de vida da população guanambiense.

\section{METODOLOGIA}

A área do estudo compreende a cidade de Guanambi (BA), que está localizada entre as coordenadas

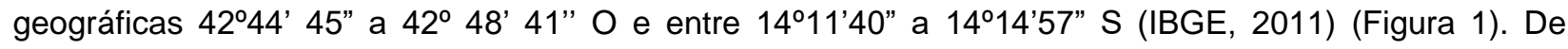
acordo com o censo do IBGE (2010), o município apresentou um total de 78.833 habitantes, destes 62.565 moradores na área urbana e 16.268 na zona rural, sendo que 58.111 pessoas localizavam-se na sede municipal. A população estimada do ano de 2019 alcançou 84.481 moradores (IBGE, 2019).

Situado no Semiárido baiano, o município de Guanambi é caracterizado por médias de temperaturas anuais superiores a $24^{\circ} \mathrm{C}$ e precipitações pluviométricas abaixo de 800 milímetros (ARAÚJO, 2011). Além disso, os padrões climáticos apresentam variações espaço-temporais (MOURA et al., 2007). A municipalidade possui fitofisionomias, predominantes, da Floresta Estacional Decidual (FED) e Caatinga (PROBIO, 2004).

Foram utilizados como instrumentos técnicos as Geotecnologias, em específico, o Sensoriamento remoto e o Geoprocessamento. Vale ressaltar que o Sensoriamento Remoto tem como conceituação geral a coleta de dados sem o contato direto com o ser humano, por meio de sensores ativos (ex: radares), passivos (ex: satélites), entre outros. O Geoprocessamento é um conjunto de técnicas que incorporam a Cartografia Digital, o Processamento Digital de Imagens - PDI e o Sistema de Informação Geográfica SIG (ROSA, 2005,2009; NOVO, 2011; MOURA, 2014).

Desse modo, utilizou-se como produto orbital a imagem do satélite GeoEye, datada de 05 de agosto de 2014, disponibilizada pelo Centro Universitário UniFG/Observatório UniFG do Semiárido Nordestino. Foi adotada a classificação supervisionada da Árvore de Decisão (Decision Tree) no software ENVI 5.5, licenciado pelo Centro Universitário UniFG, pacote ENVI laboratório (25 acessos). O procedimento técnico Árvore de Decisão caracteriza-se pela constituição de estágios com decisões binárias, para cada decisão a delimitação de um conjunto de pixels (PAL e MATHER, 2003; MAEDA et al., 2011). Os intervalos espectrais da imagem GeoEye e os valores do Normalized Difference Vegetation Index (NDVI) (oriundos da GeoEye) foram usados para a arquitetura da Árvore de Decisão. O NDVI tem como intervalos escalares a variação entre $-1 \mathrm{a}+1$, sendo que quanto mais próximo de 1 , maior a densidade de cobertura vegetal, e como referência a equação 1 (ROSENDO, 2005).

$N D V I=\frac{\text { IVP-V }}{\text { IVP }+\mathrm{V}}$

Sendo:

IVP: Canal do infravermelho próximo; e

V: Canal no vermelho. 
Figura 1 - Localização da cidade de Guanambi (BA).

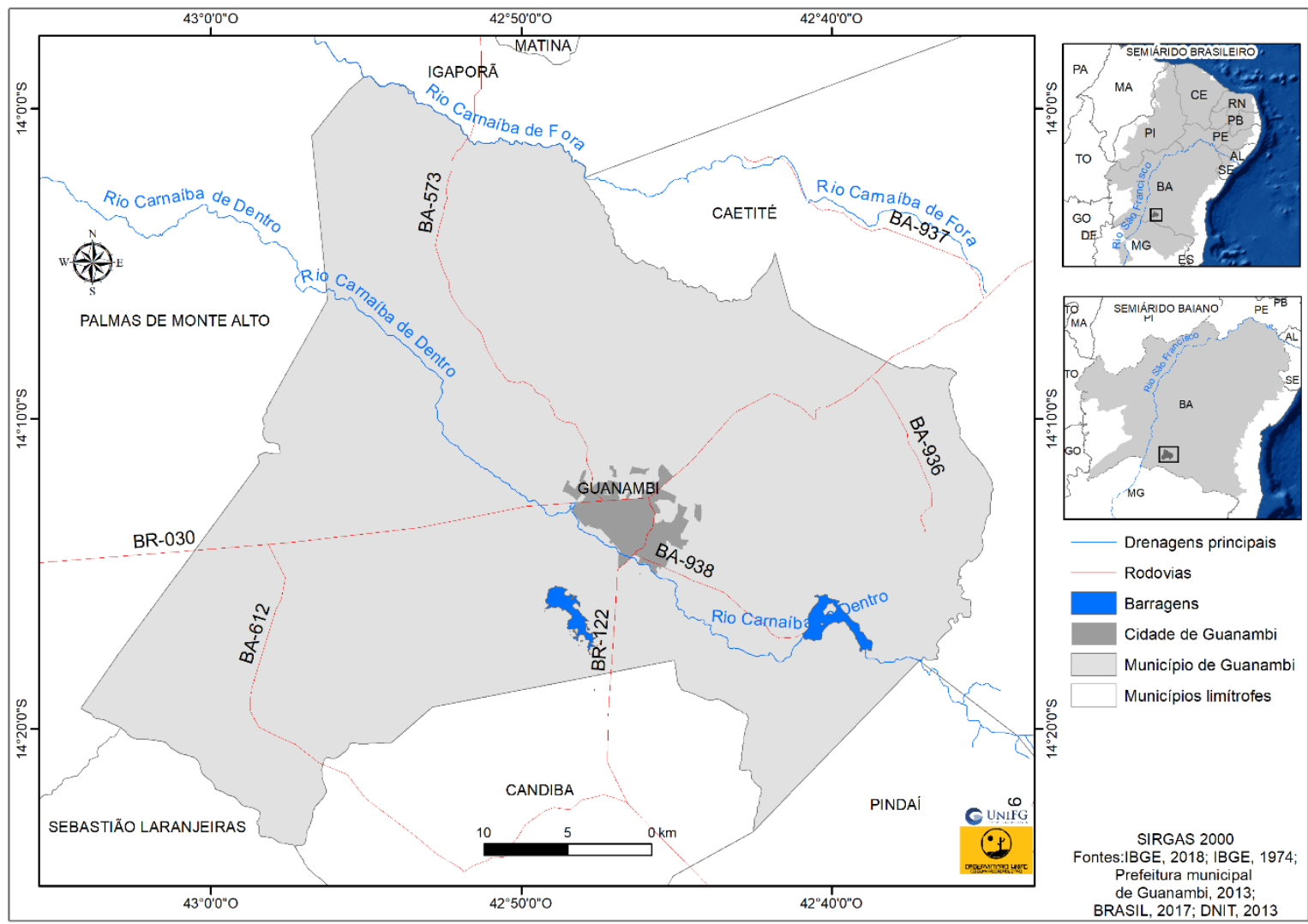

Fontes - IBGE, 1974, 2018; GUANAMBI, 2013; BRASIL, 2017; DNIT, 2013.

Vale ressaltar que para a classificação foi considerada o distrito sede ou cidade de Guanambi, adotada a escala de mapeamento foi de 1:10.000 e foram realizados levantamentos de campo para validações dos dados.

Em ambiente SIG, após a etapa de classificação do produto orbital, foram realizadas as fotointerpretações e ajustes das poligonais, estas sobrepostas à imagem GeoEye. Para a quantificação da arborização, consideraram-se os logradouros, base cartográfica vetorial (linhas), disponibilizados pela Prefeitura Municipal de Guanambi (BA) do ano de 2013. O formato repassado pelo órgão executivo municipal foi em formato DWG, oriundo da técnica Computer Aided Design (CAD), sendo necessário a transformação e adequações, alfanuméricas georreferenciadas, para o formato shapefile (limites de bairros e logradouros). Também, foram vetorizados os principais reservatórios de água da cidade e 0 ajuste da hidrografia urbana (ajuste da base hidrográfica do IBGE - SD-23-Z-B-II) na imagem GeoEye 2014. Todo o procedimento supramencionado foi desenvolvido no software ArcGIS 10.2.2, licenciado pelo Centro Universitário UniFG, pacote educacional (Desktop Advanced; Spacial Analyst; 3D Analyst).

Posteriormente, realizaram-se os cálculos de Índice de Cobertura Vegetal (ICV) e Índice de Cobertura Vegetal por Habitante (ICVH) (GOMES e QUEIROZ, 2011). Utilizaram-se os parâmetros da Sociedade Brasileira de Arborização Urbana (SBAU) de $15 \mathrm{~m}^{2} /$ habitante para ICVH. Com isso, foram empregadas as equações 2 e 3:

$$
\begin{aligned}
& I C V=\frac{\Sigma \text { das åreas das copas }}{\Sigma \text { das áreas dos bairros }} * 100 \\
& I C V H=\frac{\Sigma \text { das åreas de copa }}{\mathrm{n}^{\circ} \text { de habitantes da cidade }}
\end{aligned}
$$


Também, posteriormente, foram utilizadas as diretrizes da Organização das Nações Unidas (ONU) para a classificação do ICV nos bairros da cidade de Guanambi (Quadro 1).

Quadro 1 - ICV de acordo com a ONU.

\begin{tabular}{|c|c|}
\hline Classificações & Descrições \\
\hline Condições boas & ICV $>30 \%$ \\
\hline Condições regulares & $5 \%<\mathrm{ICV}<30 \%$ \\
\hline Condições Ruins & $\mathrm{ICV}<5 \%$ \\
\hline
\end{tabular}

Fontes - Silva, 2016; Silva et al., 2018.

Para analisar os padrões espaciais da cobertura vegetal, fez-se uso dos parâmetros da forma, conexões e contiguidade da vegetação (JIM, 1989). A vegetação foi avaliada de acordo com três critérios, que contemplam nove categorias distintas de configuração de cobertura vegetal, sendo essas: a isolated (dispersed, clustered e cumpled), linear (rectilinear, curvilinear e anular) e connected (reticulate, ramified e contínuous). Salienta-se também o emprego de análise qualitativa, sendo realizada a fotointerpretação das feições em ambiente SIG, software ArcGIS 10.2.2, de acordo com os padrões a seguir (Figura 2).

Figura 2 - Esquema de classificação para cobertura vegetal urbana.
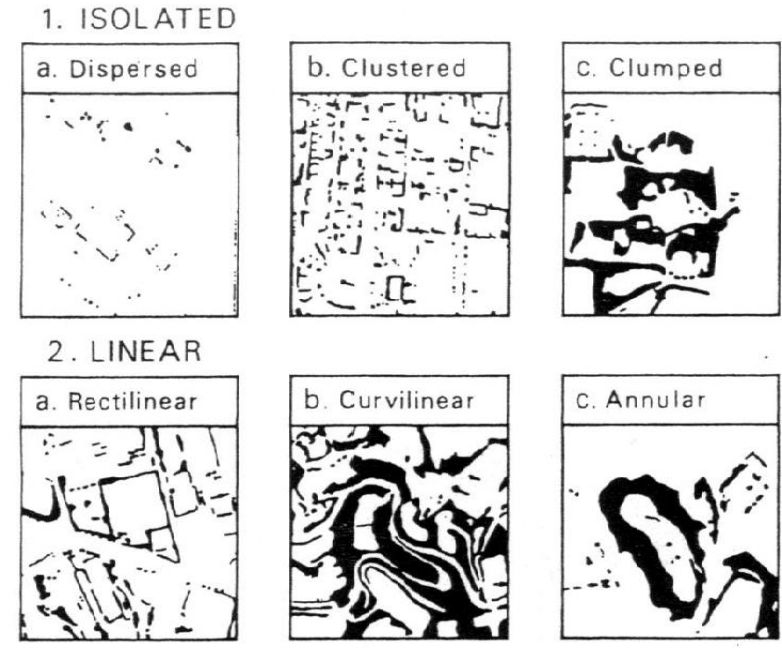

3. CONNECTED

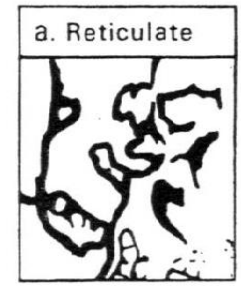

Tree canopy cover
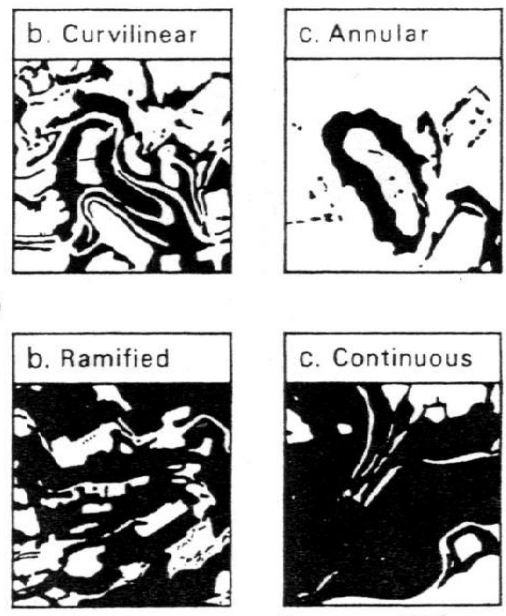

Fonte - JIM (1989).

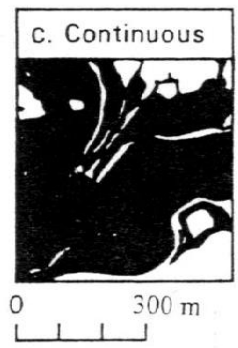




\section{COBERTURA VEGETAL E ARBORIZAÇÃO DA CIDADE DE GUANAMBI (BA)}

A cobertura vegetal apresenta funções essenciais que visam garantir a qualidade de vida dos citadinos, tais como: estabilizar a temperatura dos solos; filtrar o ar; equilibrar o índice de umidade da cidade; diminuir a poluição sonora; entre outros benefícios que corroboram com a importância da presença da vegetação nas cidades ( $\mathrm{NUCCl}, 2008)$. Diante desta conjuntura, os espaços urbanos com expressiva quantidade de vegetação, especialmente arbórea e arbustiva, tendem a causar um bem-estar físico e emocional aos seus habitantes (MOURA e NUCCI, 2005).

No caso da cidade de Guanambi (BA), foi encontrado um total de $734.613,469 \mathrm{~m}^{2}$ de cobertura vegetal e $217.616,161 \mathrm{~m}^{2}$ da categoria arborizada (Figura 03). Os bairros ou loteamento com quantidades maiores de cobertura vegetal foram: São Francisco $\left(60.856,421 \mathrm{~m}^{2}\right)$; Paraíso $\left(36.716,793 \mathrm{~m}^{2}\right)$; Centro $(36.433,130$ $\left.\mathrm{m}^{2}\right)$; Alto Caiçara (33.347,302 m²); Vomitamel (30.949,385 m²); Brasília $\left(30.421,953 \mathrm{~m}^{2}\right)$; e Santo Antônio $\left(30.385,073 \mathrm{~m}^{2}\right)$. A semelhança entre esses bairros e loteamentos é o tamanho territorial expressivo em relação aos demais. Isso pode mascarar as informações, pois foi selecionada somente a cobertura vegetal sem considerar os limites dos bairros ou loteamentos.

Neste sentido, percebe-se uma baixa quantidade de mancha de cobertura vegetal e arborização nos sentidos leste, sudeste, norte e nordeste do tecido urbano. Em específico, nas áreas de habitações de programas governamentais de baixa renda, como por exemplo, o Monte Azul e Gorungas e também a norte-nordeste da cidade, nos condomínios de média e alta renda, como o Park Boulevard e Eco Resort. Assim, alerta-se para a necessidade de se direcionar esforços para o desenvolvimento de políticas públicas que vislumbrem o plantio de espécies apropriadas nas áreas supramencionadas da cidade de Guanambi, tendo como enfoque o aumento da qualidade de vida da população, além de contemplar a cidade em sua totalidade (Figura 03).

Nos casos das proximidades dos loteamentos Santo Antônio e Maria Bastos (sul da mancha urbana), observou-se que o ambiente apresenta fragmentos de vegetação nas proximidades do canal do rio Carnaíba de Dentro e no loteamento Olinda (norte da cidade), também foram evidenciados. De acordo com a Lei 12.651, o Código Florestal, estas manchas de vegetação caracterizam Áreas de Preservação Permanente (APP). Porém, são coberturas vegetais com espécies exóticas e uma vegetação secundária (Figura 3).

Desse modo, a conjuntura regional que contempla a área de estudo, semiárido baiano, reforça que a preservação e expansão de cobertura vegetal se torna importante, pois a região é caracterizada por uma evapotranspiração intensa e extensos períodos anuais de estiagem de precipitação pluviométrica (MOURA et al., 2007).

A cidade de Guanambi apresentou um ICVH de 12,63 m²/hab., considerando a população de 58.111 moradores. O valor encontra-se abaixo da sugestão definida pela SBAU, que apresenta o mínimo de cobertura vegetal por habitante de $15 \mathrm{~m}^{2}$ (SBAU, 1996). O baixo ICVH encontrado na área urbana de Guanambi é caracterizado pela presença de vazios de cobertura vegetal nas regiões periféricas da cidade, principalmente em áreas dos programas governamentais habitacionais e em loteamentos recentes.

Em relação ao ICV, que avalia a quantidade de cobertura vegetal considerando os limites dos bairros ou loteamentos, tiveram como melhores indicadores as localidades intraurbanas dos loteamentos Vila Nova $(7,17 \%)$, Bom Jesus $(7,02 \%)$, Urbis $(6,47 \%)$, Beija Flor I $(6,41 \%)$, Vasconcelos $(5,83 \%)$, Bela Vista $(5,76 \%)$, Olinda $(5,67 \%)$, Marabá $(5,31 \%)$, Santa Luzia $(5,32 \%)$, Santo André $(5,09 \%)$, Vomitamel $(4,95 \%)$, Centro $(4,94 \%)$ e Alvorada $(4,83 \%)$ (Figura 4$)$. Os loteamentos da região sul-sudeste 
concentram baixos indicadores de ICV, não sendo detectado nenhum registro nas áreas periféricas salienta-se que a parte leste, nordeste e norte, também seguem o mesmo padrão do ICVH (Figura 4). Com isso, percebe-se uma concentração espacial de cobertura vegetal em determinados loteamentos da cidade. A partir da análise por meio de trabalhos de campo na cidade de Guanambi, foram detectados poucos indicativos de plantio árvores, principalmente nos locais de estabelecimentos dos programas habitacionais populares. Assim, 84\% dos loteamentos encontram-se em situações insatisfatórias de cobertura vegetal, sendo $12 \mathrm{com}$ nenhuma ou poucas árvores (Figura 4). De acordo com a ONU, áreas cobertas para garantir a qualidade de vida configura-se um ICV maior de 30\% (SILVA, 2016; SILVAL et al., 2018). A cidade de Guanambi não detém loteamentos com indicadores maiores que $30 \%$ e somente 12 encontram-se em condições regulares, porém próximos aos limiares de 5\%. É importante destacar que áreas com ICV inferiores a $5 \%$ são consideradas como áreas muito deficitárias em relação a cobertura vegetal (BUCCHERI FILHO e NUCCI, 2011).

Figura 3 - Cobertura vegetal e arborização na cidade de Guanambi (BA).

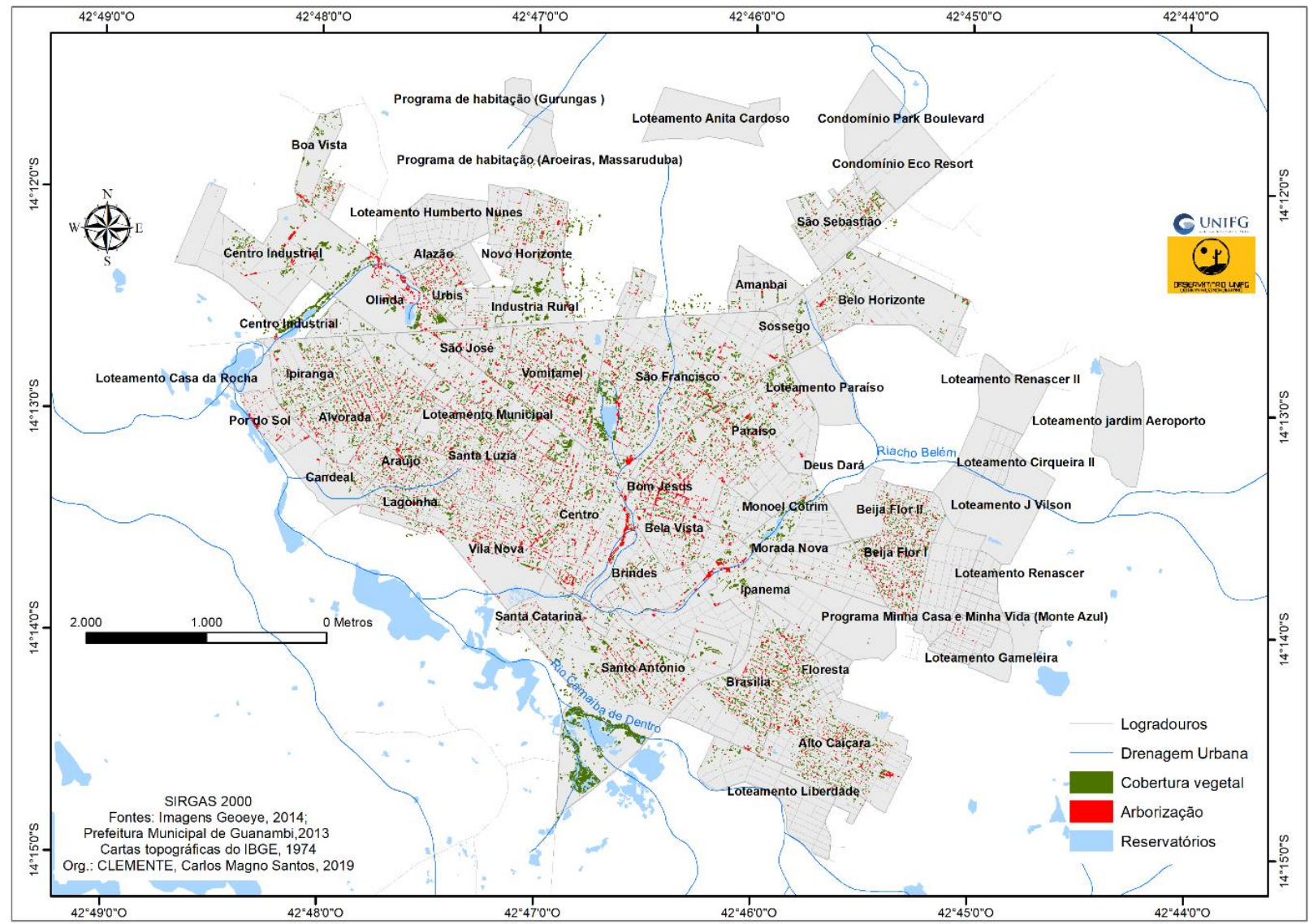

Fontes - GeoEye 2014; GUANAMBI, 2013; IBGE, 1974.

O Plano Diretor Participativo do município de Guanambi de 2007, no artigo 14, destaca o "incentivo à arborização como elemento integrador e de conforto ambiental" (GUANAMBI, 2007, pag. 09). Porém, os dados da presente pesquisa revelam pouca efetividade desse aparato legal municipal para o incentivo da arborização na cidade, considerando os 12 anos de existência do Plano Diretor (2007 a 2019). E de maneira geral, as cidades vêm perdendo, gradativamente, a sua qualidade ambiental em virtude de uma 
urbanização rápida e da presença de planos urbanos deficitários (MILANO e DALCIN, 2000). E o poder Público Municipal diante do problema, em sua maioria, não consegue adotar políticas públicas que visem à reparação deste cenário (MOURA e NUCCI, 2005).

Figura 4 - Índice de Cobertura Vegetal - ICV na cidade de Guanambi (BA).

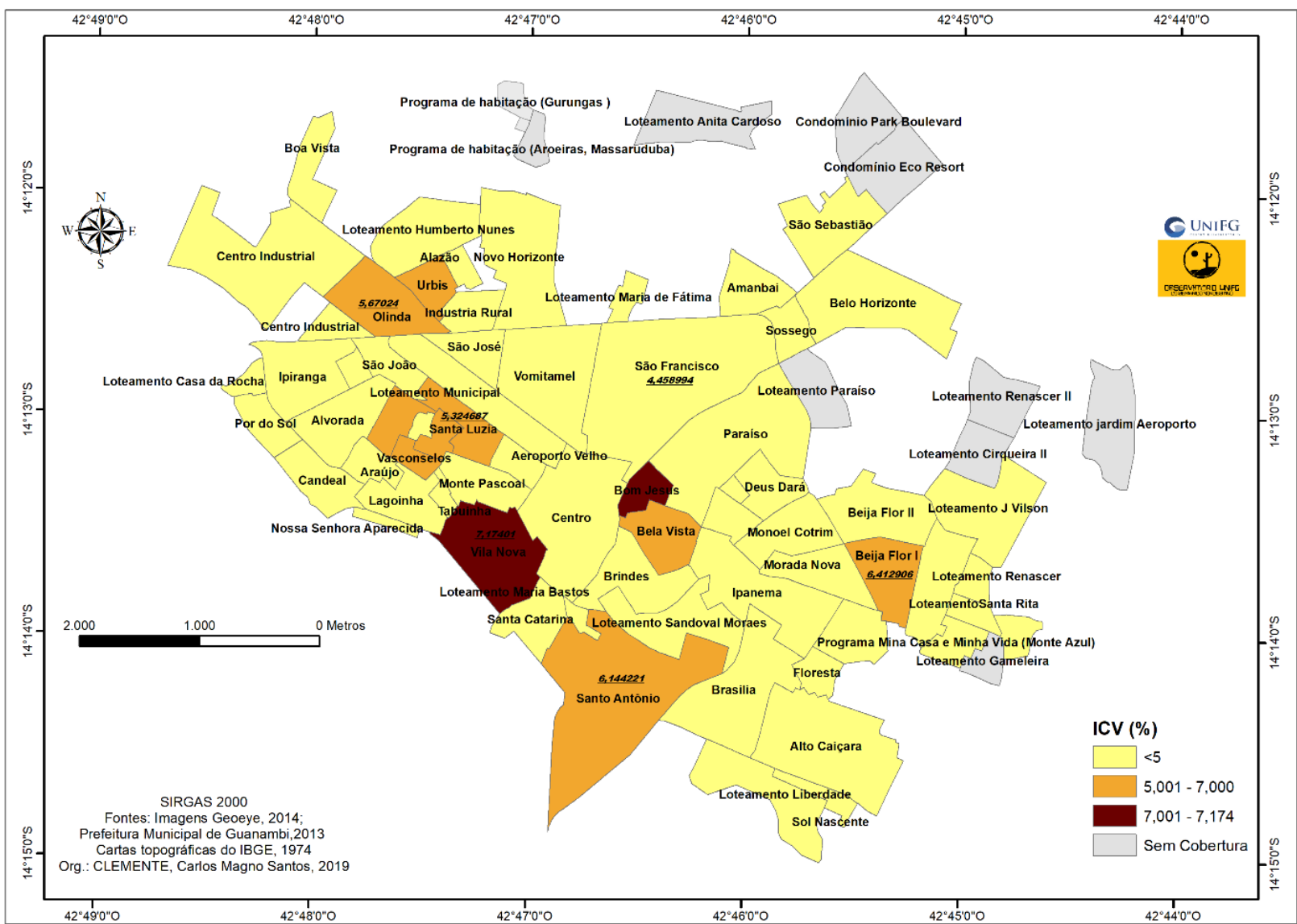

Fontes - GeoEye (2014); GUANAMBI, 2013; IBGE, 1974.

No que concerne sobre a classificação da cobertura vegetal de acordo com JIM (1989), foi selecionada à categoria isolated, pois se detectou a predominância de árvores com localizações esparsas e distantes entre si (Figura 5). E o padrão de conexão e contiguidade dispersed, principalmente, pelo fato das árvores estarem em pequenos agrupamentos, distantes, localizadas em canteiros e dentro de alguns loteamentos, assim observa-se uma configuração espacial que se repete na mancha urbana de Guanambi (Figura 5). Com isso, como sugerido por Moura e Nucci (2005), recomenda-se uma estruturação de cobertura vegetal no espaço geográfico com o intuito de realizar conexões entre os elementos naturais.

Diante da conjuntura, ressalta-se que o verde presente no cenário urbano é um atributo relevante para garantir a qualidade de vida dos citadinos, sendo a vegetação apresentada em ambientes urbanos um fator relevante para o equilíbrio emocional das crianças, bem-estar físico dos habitantes, entre outros benefícios (MOURA e NUCCI, 2005; MONTEIRO, 1976; LOMBARDO, 1985). Além disso, a conservação da cobertura vegetal urbana traz benefícios para a população ou serviços ecossistêmicos como a regulação de temperatura, aspectos paisagísticos para incrementos turísticos, infiltração das águas nos 
solos, habitats para pássaros, elevação dos insetos polinizadores, biomassa para armazenamento de carbono, entre outros (GÓMEZ-BAGGETHUN e BARTON, 2013).

Entretanto, há uma falta de preparo e conhecimento a respeito desse elemento nas diretrizes dos planejamentos das cidades (MONTEIRO, 1976; LOMBARDO, 1985). Com isso, compete ao ente público municipal a constituição de legislações e aplicações destas para melhoria da qualidade de vida dos citadinos, bem como a de incentivar a participação da sociedade nos conselhos da cidade e meio ambiente, pois é um interessante canal para instigar a participação e o controle social.

Figura 5 - Carta imagem da classificação isolated e dispersed.

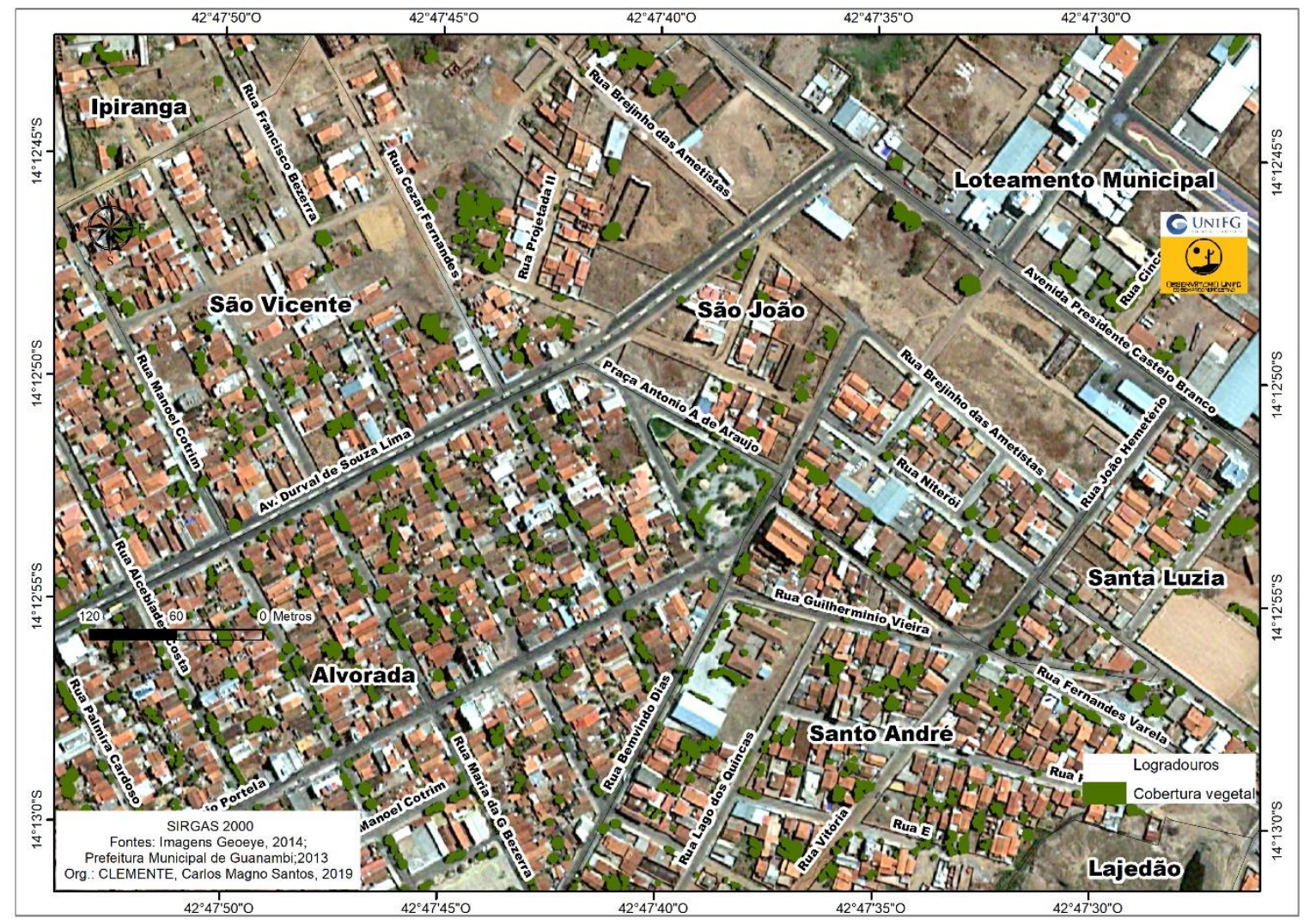

Fontes - GeoEye (2014); GUANAMBI (2013).

\section{CONSIDERAÇÕES FINAIS}

O presente estudo conclui que os índices da cobertura vegetal e arborização na cidade de Guanambi encontram-se distantes dos parâmetros recomendados pelas organizações mundiais para melhoria da qualidade de vida dos citadinos, sendo que mais de $80 \%$ dos loteamentos estão classificados em situações insatisfatórias e inadequadas. É válido destacar que de acordo com as diretrizes nacionais e internacionais, nenhum loteamento da cidade apresenta indicadores em boas condições e compatibilidade de cobertura vegetal e arborização.

Há que se ressaltar que mesmo o Plano Diretor Participativo do município de Guanambi estabelecendo que a arborização é um elemento importante, integrador e responsável pelo conforto ambiental, no aspecto prático e fático tais elementos não foram observados nas análises por meio de Sensoriamento Remoto, Geoprocessamento e nas análises de campo. Neste sentido, esta pesquisa sugere a formulação e aplicação de políticas públicas que efetivamente busquem a melhoria dos indicadores referentes à

Caminhos de Geografia $\quad$ Uberlândia $\quad$ v. 20, n. $72 \quad$ Dez/2019 $\quad$ p. 136-148 Página 144


cobertura vegetal e arborização na cidade de Guanambi, principalmente nas áreas periféricas, loteamentos recentes e nos locais escolhidos para instalação dos programas habitacionais governamentais populares. Recomenda-se também a reestruturação das áreas verdes nas praças e no Parque da cidade de Guanambi e a criação de canais participativos que repensem a cobertura vegetal e a arborização na área urbana do município.

Assim, finaliza-se o presente estudo destacando que a real preocupação e adoção de medidas que busquem a efetiva conservação e aumento da cobertura vegetal e arborização na cidade em Guanambi melhorará a qualidade de vida e convivência dos cidadãos com a seca, além de possibilitar outras benesses sociais e ambientais para as presentes e futuras gerações

\section{AGRADECIMENTOS}

Agradecimentos ao Centro Universitário FG - UniFG pelo apoio financeiro, científico e de infraestrutura.

Ao Observatório UniFG do Semiárido Nordestino e o laboratório de Geoprocessamento do Observatório UniFG pelo suporte técnico-científico, sobretudo no que tange às análises socioespaciais, Sensoriamento Remoto e Geoprocessamento.

\section{REFERÊNCIAS}

ARAÚJO, S.M.S. A região semiárida do nordeste do Brasil: Questões Ambientais e Possibilidades de uso Sustentável dos Recursos. Rios Eletrônica- Revista Científica da Fasete, Paulo Afonso, v. 5, n. 5, p.110, dez. 2011. Disponível em:

<https://www.fasete.edu.br/revistarios/media/revistas/2011/5/a_regiao_semiarida_do_nordeste_do_brasil. pdf>. Acesso em: 28 set. 2019.

BRASIL. Resolução no 115, de 23 de novembro de 2017. 1. ed. Brasília, Distrito Federal, 15 dez. 2017. n. 232, Seção 1, p. 26-34. Disponível em: <http://www.in.gov.br/materia/-

/asset_publisher/Kujrw0TZC2Mb/content/id/739568/do1-2017-12-05-resolucao-n-115-de-23-denovembro-de-2017-739564>. Acesso em: 26 set. 2019.

BUCCHERI FILHO, AI.T; NUCCI, J.C. Espaços livres, áreas verdes e cobertura vegetal no bairro alto da XV, Curitiba/PR. Revista do Departamento de Geografia, São Paulo, v. 18, p.48-59, abr. 2011. Disponível em: <http://www.revistas.usp.br/rdg/article/view/47264/51000>. Acesso em: 28 set. 2019. https://doi.org/10.7154/RDG.2006.0018.0005

CAVALHEIRO, F; DEL PICCHIA, P.C.D. Áreas verdes: conceitos, objetivos e diretrizes para o planejamento. In: $1^{\circ}$ Congresso Brasileiro Sobre Arborização Urbana e $4^{\circ}$ Encontro Nacional Sobre Arborização Urbana. Vitória: Anais... Congresso Brasileiro Sobre Arborização Urbana e $4^{\circ}$ Encontro Nacional Sobre Arborização Urbana, 1992. p. 29 - 38. Disponível em:

$<$ https://docplayer.com.br/19500059-Areas-verdes-conceitos-objetivos-e-diretrizes-para-oplanejamento.html>. Acesso em: 28 set. 2019.

COSTA, R. G. S; FERREIRA, C. C. M.. Análise do Índice de Áreas Verdes (IAV) na área central da cidade de Juiz de Fora, MG. Revista da Sociedade Brasileira de Arborização Urbana, Piracicaba, v. 4, n. 1, p.39-57, mar. 2009. Disponível em: <https://revistas.ufpr.br/revsbau/article/view/66240/38117>. Acesso em: 28 set. 2019. https://doi.org/10.5380/revsbau.v4i1.66240

COSTA, R. G. S; FERREIRA, C. C. M. Biogeográfico das áreas verdes e da arborização ligada ao sistema viário na região central da cidade de Juiz de Fora (MG). Caminhos da Geografia, Uberlândia, v. 8, n. 22, p.143-153, set. 2007. Disponível em:

<http://www.seer.ufu.br/index.php/caminhosdegeografia/article/view/15554>. Acesso em: 28 set. 2019.

DIGITALGLOBE. CENTRO UNIVERSITÁRIO UNIFG. Imagem do satélite Geoye.. Observatório UniFG do Semiárido Nordestino. 2014. Escala de 1:10.000. 
DNIT - Departamento Nacional de Infraestrutura de Transportes -. Rodovias (shapefiles). 2013.

Disponível em: <http://dnit.gov.br/mapas-multimodais/shapefiles>. Acesso em: 28 set. 2019.

GOMES, M.F; QUEIROZ, D.R.E. Avaliação da Cobertura Vegetal Arbórea na Cidade de Birigui com Emprego de Técnicas de Geoprocessamento e Sensoriamento Remoto. Revista Geografar, Curitiba, v. 6, n. 2, p.93-117, dez. 2011. Disponível em: <https://revistas.ufpr.br/geografar/article/view/21579/16958>. Acesso em: 28 set. 2019. https://doi.org/10.5380/geografar.v6i2.21579

GÓMEZ-BAGGETHUN, E; BARTON, D.N. Classifying and valuing ecosystem services for urban planning. Ecological Economics, v. 86, p.235-245, fev. 2013. Disponível em:

<https://www.sciencedirect.com/science/article/pii/S092180091200362X\#!>. Acesso em: 28 set. 2019. https://doi.org/10.1016/j.ecolecon.2012.08.019

GUANAMBI (Município). Base cartográfica da cidade de Guanambi. 2013.

Lei no 223, de 04 de dezembro de 2007. Dispõe sobre a instituição do Plano Diretor Participativo do Município Guanambi e dá outras providências. Guanambi, BAHIA: Prefeitura Municipal de Guanambi, 04 dez. 2007. p. 1-56. Disponível em:

<http://www.guanambi.ba.gov.br/arquivos/093528201930071.pdf>. Acesso em: 28 set. 2019.

IBGE - Instituto Brasileiro de Geografia e Estatística -. Carta Topográfica Folha SD-23-Z-B-II. 1974. Disponível em: <https://portaldemapas.ibge.gov.br/portal.php\#mapa17275>. Acesso em: 29 set. 2019.

Censo demográfico 2010. 2011. Disponível em: <http://www.censo2010.ibge.gov.br>. Acesso em: 29 set. 2019.

.Estimativas populacionais 2019. 2019. Disponível em:

<https://www.ibge.gov.br/estatisticas/sociais/populacao/9103-estimativas-depopulacao.html?=\&t=downloads>. Acesso em: 29 set. 2019.

Malhas territoriais (municípios) 2018. 2018. Disponível em: <https://www.ibge.gov.br/geociencias/downloads-geociencias.html>. Acesso em: 29 set. 2019.

JIM, C. Y.. Tree-Canopy Characteristics and Urban Development in Hong Kong. American Geographical Society, Nova York, v. 2, n. 79, p.210-225, abr. 1989. Disponível em:

<https://www.jstor.org/stable/215527?seq=1\#page_scan_tab_contents>. Acesso em: 29 set. 2019. https://doi.org/10.2307/215527

LOMBARDO, M.A. Ilha de calor nas metrópoles. O exemplo de São Paulo. São Paulo: Hucitec, 1985, $244 p$.

MAEDA, E. E., ARCOVERDE, G. F. B., PELLIKKA, P. K. E., SHIMABUKURO, Y.E. Fire risk assessment in the Brazilian Amazon using MODIS imagery and change vector analysis. Applied Geography. v. 31, 76 - 84. 2011. https://doi.org/10.1016/..apgeog.2010.02.004

MARICATO, E.. Metrópole, legislação e desigualdade. Estudos Avançados, São Paulo, v. 17, n. 48, p.151-167, ago. 2003. Disponível em: <http://www.scielo.br/pdf/ea/v17n48/v17n48a13.pdf>. Acesso em: 29 set. 2019. https://doi.org/10.1590/S0103-40142003000200013

MILANO, M.; DALCIN, E. Arborização de vias públicas. Rio de Janeiro: LIGHT, 2000. 226 p.

MONTEIRO, C.A de F. Teoria e clima urbano. 25. São Paulo: IGEOG/USP, 1976. 181p. (Série teses e Monografias, 25).

MOURA, A.; NUCCI, J. C. Análise da cobertura vegetal de Santa Felicidade, Curitiba/PR. In: XI Simpósio Brasileiro de Geografia Física Aplicada, 2005, São Paulo/SP. Anais. São Paulo: USP, 2005.

MOURA, A. C. M.. Geoprocessamento na Gestão e Planejamento Urbano. $3^{\circ}$. ed. Rio de Janeiro: Editora Interdeciências, 2014. 312 p.

MOURA, M. S. B.; GALVÍNCIO, J. D. ; BRITO, L.T.L ; SOUZA, L.S.B; SÁ, I.I.S ; SILVA, T. G. F. Clima e água de chuva no Semi-Árido. In: BRITO, L.T.L.; MOURA, M.S.B.; GAMA, G.F.B.. (Org.).

Potencialidades da água de chuva no Semiárido brasileiro. 1ed.Petrolina: Embrapa Semi-Árido, 2007, 
v. 1, p. 37-59. Disponível em: <

https://www.alice.cnptia.embrapa.br/bitstream/doc/159649/1/OPB1515.pdf>. Acesso em: 29 set. 2019.

NOVO, E. M. L M.. Sensoriamento Remoto: Princípios e Aplicações.4º ed. São Paulo: Blucher, 2011. $387 \mathrm{p}$.

NUCCI, J C; CAVALHEIRO, F. Cobertura vegetal em áreas urbanas: Conceito e método. Revista GEOUSP: Espaço e tempo, São Paulo n.6, p.29-36, 1999. Disponível em:

<http://www.revistas.usp.br/geousp/article/view/123361/119697>. Acesso em: 05 nov. 2019.

NUCCI, J.C. Qualidade ambiental e adensamento urbano: um estudo de ecologia e planejamento da paisagem aplicado ao distrito de Santa Cecília (MSP) 2ª Edição. - Curitiba: O Autor, 2008. 150p.

Disponível em: < https://tgpusp.files.wordpress.com/2018/05/qualidade-ambiental-e-adensamentourbano-nucci-2008.pdf>. Acesso em: 29 set. 2019.

OLIVEIRA, C. H.. Planejamento ambiental na Cidade de São Carlos (SP) com ênfase nas áreas públicas e áreas verdes: diagnósticos e propostas. 1996. 181 f. Dissertação (Mestrado) - Curso de Programa de Pós-graduação em Ecologia e Recursos Naturais, Centro de Ciências Biológicas e da Saúde, Universidade Federal de São Carlos, São Carlos, 1996. Disponível em:

<https://repositorio.ufscar.br/bitstream/handle/ufscar/1950/mestrado-carlos-henke-

oliveira.pdf?sequence=1>. Acesso em: 29 set. 2019.

PAL, M.; MATHER, P. M.. An assessment of the effectiveness of decision tree methods for land cover classification. Remote Sensing Of Environment, ., v. 86, n. , p.554-565, maio 2003. Disponível em: $<$ http://www.dl.edi-

info.ir/An\%20assessment\%20of\%20the\%20 effectiveness\%20of\%20decision\%20tree\%20methods\%20for \%20land\%20cover\%20classification.pdf>. Acesso em: 29 set. 2019.

PIVETTA, K. F. L.; SILVA FILHO, D. F. Arborização Urbana. Boletim acadêmico. UNESP/FCAV/FUNEP, Jaboticabal, SP - 2002.

PROBIO - PROGRAMA DE CONSERVAÇÃO E UTILIZAÇÃO SUSTENTÁVEL DA DIVERSIDADE BRASILEIRA. Levantamento da cobertura vegetal do uso do solo do bioma caatinga. 2004.

Disponível em <

http://mapas.mma.gov.br/geodados/brasil/vegetacao/vegetacao2002/caatinga/documentos/relatorio_ final.pdf>. Acesso em 10 de jun. de 2019.

RICHTER, G. Handbuch Stadtgrün: Landschaftsarchitektur im städtischen Freiraum. Berlin: München U.a., Blv, 1981. 319 p.

ROSA, R. Geotecnologias na Geografia Aplicada. Revista do Departamento de Geografia, São Paulo, v. 16, n. 1, p.81-90, mar. 2005. Disponível em: <http://www.revistas.usp.br/rdg/article/view/47288/51024>. Acesso em: 29 set. 2019. https://doi.org/10.7154/RDG.2005.0016.0009

ROSA, R. Introdução ao Sensoriamento Remoto. $7^{\circ}$. ed. Uberlândia: Edufu, 2009. 260 p. https://doi.org/10.14393/EDUFU-978-85-7078-219-9

ROSENDO, J. S.. Índices de vegetação e monitoramento do uso do solo e cobertura vegetal na bacia do rio Araguari - MG - utilizando dados do sensor MODIS. 2005. 130 f. Dissertação (Mestrado) Curso de Programa de Pós-graduação em Geografia, Instituto de Geografia, Universidade Federal de Uberlândia, Uberlândia, 2005. Cap. 2005. Disponível em:

<http://ecologia.ib.usp.br/lepac/bie5759/jussara_santos.pdf>. Acesso em: 29 set. 2019.

SBAU - SOCIEDADE BRASILEIRA DE ARBORIZAÇÃO URBANA. "Carta a Londrina e Ibiporã”. Boletim Informativo, v.3, n.5, p.3, 1996.

SILVA, D. C. C.. Proposta metodológica para elaboração de um índice espacial de sustentabilidade ambiental aplicado a bacias hidrográficas. 2016. $158 \mathrm{f}$. Tese (Doutorado) - Curso de Programa de Pós-graduação em Ciências Ambientais, Instituto de Ciência e Tecnologia (câmpus de Sorocaba), Universidade Estadual Paulista "júlio de Mesquita Filho", Sorocaba, 2016. Disponível em: 
<https://repositorio.unesp.br/bitstream/handle/11449/144610/silva_dcc_dr_soro.pdf?sequence=3\&isAllow ed $=\mathrm{y}>$. Acesso em: 29 set. 2019.

SILVA, D. C. C., GRANDIN, G., SIMONETTI, V.C., SILVA, D.C.C. Análise da cobertura vegetal no centro urbano do município de Salto de Pirapora (SP). Caminhos de Geografia, Uberlândia - MG, v. 19, n. 68, 2018, p. 361-371. Disponível em: <

http://www.seer.ufu.br/index.php/caminhosdegeografia/article/view/40848/24878>. Acesso em: 29 set.

2019. https://doi.org/10.14393/RCG196824

Recebido em: 26/05/2018

Aceito para publicação em: 26/11/2019 